\title{
Examining the Mediating Effects of Stress on Fear of COVID-19 and Well-being Using Structural Equation Modeling
}

\author{
Remya Lathabhavan ${ }^{1}$ (D) Shivani Vispute ${ }^{2}$
}

Accepted: 8 May 2021 / Published online: 18 May 2021

(C) The Author(s), under exclusive licence to Springer Science+Business Media, LLC, part of Springer Nature 2021

\begin{abstract}
This study focuses on the effects of fear factor due to COVID-19 on stress and well-being of college students in India. The authors conducted a cross-sectional survey among 625 Indian students across various Indian universities and structural equation modeling (SEM) has been performed for analyzing the data. The findings of the study show a positive effect of fear of COVID-19 on stress with $\beta=.27, p<0.05$, and a negative effect on well-being $(\beta=-.13, p<0.05)$. The results also depicted the mediating role of stress between fear of COVID-19 and well-being. Therefore, it is suggested that measures must be taken by individuals, society, and policy makers to include mental health maintenance in the pandemic response activities. Further longitudinal studies in different geographical regions and demographics can provide a more generalized understanding of the relationship between the pandemic and mental health. The limitations, policy implications, and suggestions are discussed.
\end{abstract}

Keywords COVID-19 $\cdot$ Fear of COVID-19 $\cdot$ Mental health $\cdot$ Stress $\cdot$ Well-being $\cdot$ Students

The novel coronavirus disease (COVID-19) outbreak has raised numerous concerns in public health (Heymann \& Shindo, 2020) in recent times. Besides fear of infection, mental health concerns among the public have also increased all over the world (Holmes et al., 2020). The COVID-19 scenario has resulted in an increased level of psychiatric issues such as stress, anxiety, depressive symptoms, insomnia, denial, anger, fear and, in the worst case, suicide (Torales et al., 2020).

Remya Lathabhavan

remya.1@vit.ac.in

Shivani Vispute

shivanivispute1704@gmail.com

1 Department of Technology Management, VIT University, Vellore, India

2 Wipro Technologies, Bangalore, India 
Recent studies have shown the adverse psychological impacts of the COVID-19 pandemic on student community (Cao et al., 2020). Delays in the opening of schools and colleges, fear of infection to self and loved ones, and stress regarding alternate methods of learning etc. are some of the factors that have affected the mental health of students (Cao et al., 2020). There have been global reports of students committing suicide during this pandemic as well (Lathabhavan \& Griffiths, 2020; Mamun et al., 2020; Thakur \& Jain, 2020). Hence, it is very clear that such a fear phenomenon due to the pandemic situation affects the normal life style of students.

Even though the construct "fear" is a most researched psychological construct, the fear of COVID-19 is an emerging construct with a much scope for more societal implications (Pakpour \& Griffiths, 2020). At this pandemic situation, the scale has been exclusively developed to measure and ally the fear among the people towards the COVID-19 (Ahorsu et al., 2020). Extensively, the construct "fear" itself has recorded its relationship with various psychological outcomes such as stress and life satisfaction at various contexts of global environment (Blachnio \& Przepiorka, 2017; Maeng \& Milad, 2017). Moreover, considering the current scenario of uncertainty in a common person's life, studying about the fear of COVID-19 can contribute to the broader area of psychological research and practice.

Perceived stress is the degree to which, an individual assesses the situation in their lives as stressful, considering previous 1 month's status (Lee, 2012). Studies on fear and stress because of diseases attain more attention among academia and practice due to many reasons. First, fear about diseases aggravates the stress among the patients and their loved ones (Hall et al., 2017). Second, the fear of getting infected causes stress among the public (Yang et al., 2018). Children and adolescents are among the most psychologically affected groups due to pandemic (Kim et al., 2020). The COVID-19 pandemic raised these concerns and fear, as it spread across the globe rapidly (Tandon, 2020)and this indicates the need for an analysis of these aspects.

Well-being of an individual can be termed as the situation when an individual has the psychological, social, and physical resources that the person needs to meet a particular psychological, physical, or social challenge (Dodge et al., 2012). Although the relationship between fear and well-being are an established research topic in different disciplines, its comparatively less researched area in mental health discipline, especially in connection with newly emerging infectious diseases (Dumalaon-canaria et al., 2016; Koch et al., 2012).

In this contemporary world, practitioners and academicians are more interested in investigating the relationship between stress and well-being, as stress has become a common word for an individual's everyday life (Bernstein \& Chemaly, 2017; Praharso et al., 2017). The COVID-19 pandemic builds up stress among the public due to its unexpected nature of wide spread and its nature of highly infectiousness (Xiong et al., 2020).

Owing to the importance of mental health, it is the need of the hour to understand the effects of the pandemic on the mental well-being of our budding future of India, the student community. We have used a survey-based research methodology to understand the effects of various factors on the issue considered. Through this work, we would show the direct and indirect effects of fear of COVID-19 on well-being, mediated through stress. Towards this goal, the present study investigates
a. The role of fear of COVID-19 on stress
b. The direct role of fear of COVID-19 on well-being
c. The role of stress on well-being
d. The mediating role of stress on well-being.

Figure 1 depicts the proposed model for the study. 


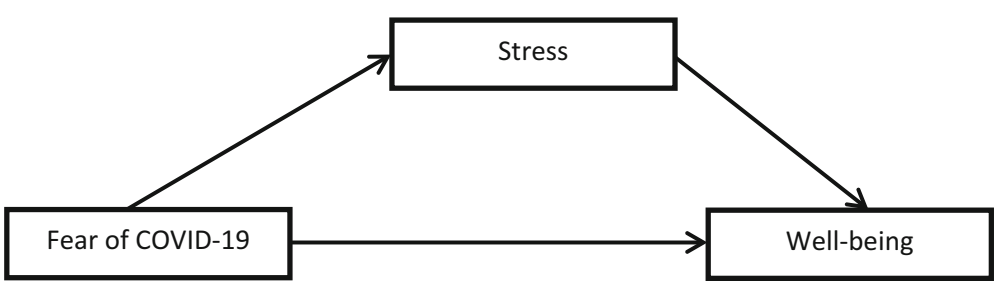

Fig. 1 Proposed model

\section{Methods}

\section{Participants and Procedures}

The sample consisted of 625 students from different universities in India. We conducted an online survey based on the preventive measures implemented in society due to COVID-19. The age group of participants was 17 to 23. Among the respondents, 389 were boys and 236 were girls. We utilized convenient sampling technique for the better reach of the survey.

The survey was conducted during the period of national lockdown in India. The authors directed the participants to analyze themselves for previous 1 month after lockdown imposition when COVID-19 cases increased drastically. We have selected perceived stress and well-being as dependent variables in order to understand the effects of FCV-19S (fear of COVID-19 scale). All the constructs were measured using a seven-point Likert-type scale ranging from 1 (strongly disagree) to 7 (strongly agree).

\section{Measures}

Fear of COVID-19 scale (FCV-19S) was measured using 7-items scale as developed by Ahorsu et al. (2020). Sample items were "I am most afraid of Corona" and "My heart races or palpitate when I think about getting Corona". The Cronbach's alpha was 0.84 for this study.

Perceived stress The short version (4-items) of Perceived Stress Scale (Cohen et al., 1983) was used for this study. A sample item is "In the last month how often have you felt you were unable to control the important things in your life?". The scale exhibited good reliability $(\alpha=0.91)$.

Well-being was measured using WHO-Five Well-being Index (WHO-5). A sample item is "I have felt calm and relaxed". The Cronbach's alpha was 0.84 for this study.

\section{Data Analysis}

Structural equation modeling (SEM) methods implemented using AMOS 24.0 (Arbuckle, 2016) were used to test the research model. Confirmatory factor analysis was performed with maximum likelihood estimation to examine the goodness of the model. The models' goodness of fit was evaluated using the criteria: relative $\chi^{2}:\left(\chi^{2} / \mathrm{df}\right)<3$, root mean square error of approximation (RMSEA): $\leqslant 0.08$, standardized root mean square residual (SRMR): $\leqslant 0.06$, normed fit index $(\mathrm{NFI}) \geqslant 0.90$, comparative fit index $(\mathrm{CFI}) \geqslant 0.90$, and Tucker-Lewis index $(T L I) \geqslant 0.90$ (Byrne, 2013; Hu \& Bentler, 1998). Cronbach's $\alpha$, average variance extracted (AVE), composite reliability (CR), and average loadings (AL) were also used to check the reliability and validity of the instruments. 


\section{Results}

\section{Descriptive Statistics}

The descriptive statistics is shown in Table 1. All significant relationships were in the expected direction.

\section{Measurement Models}

Harman's one-factor test was conducted to check for the common method bias and that the constructs in the model are distinct from each other (Podsakoff et al., 2003). It failed to demonstrate a single factor. The three-factor model revealed good fit to data with $\chi^{2} / \mathrm{df}=1.60, p<0.01, \mathrm{CFI}=0.97, \mathrm{TLI}=0.96$, RMSEA $=0.05$, and SRMR $=$ 0.04 . This findings show insignificant effect of bias on results and distinct nature of constructs (Doty \& Glick, 1998). Hence, this was considered the final measurement model for the following analyses.

\section{Reliability and Validity Measurements}

Table 2 shows the details of reliability and convergent validity. All the variables had a satisfactory level of internal consistency, having values greater than 0.7 (Nunnally, 1994). It also satisfied the criteria that CR>.60 and AVE>.50 (Bagozzi \& Yi, 1988) and thus the measurement model satisfied the conditions for reliability and convergent validity.

\section{Structural Equation Modeling(SEM)}

The results of SEM analysis showed that the proposed model (Fig. 1) is found to be fit to the data adequately with $\chi^{2} / d f=1.66, p<0.01, \mathrm{CFI}=0.95, \mathrm{TLI}=0.94$, $\mathrm{RMSEA}=0.05$, and SRMR $=0.05$. The relationship between the fear of COVID-19 and stress was significant with $\beta=.27, p<0.05$, thereby hypothesis $\mathrm{H} 1$ is accepted. The relationship between stress and well-being was also significant with $\beta=-.13$, $p<0.05$, thereby hypothesis $\mathrm{H} 2$ is accepted. At a significant level of $p<0.001$, the relationship between the fear of COVID-19 and well-being was also found to be significant with $\beta=-.22$, thereby hypothesis $\mathrm{H} 3$ is accepted. The direct and indirect effects of the fear of COVID-19 on well-being was significant with $\beta=-.18$, $p<0.001$ and $\beta=-.034, p<0.001$. This implies partial mediation of perceived stress on the relationship of fear of COVID-19 and well-being, thereby the hypothesis $\mathrm{H} 4$ is accepted (refer Fig. 2 and Table 3).

Table 1 Mean, standard deviation, and correlation of the study variables

\begin{tabular}{lccccc}
\hline & Mean & SD & Fear of COVID-19 & Perceived stress & Well-being \\
\hline Fear of COVID-19 & 2.79 & 1.56 & 0.841 & & 0.910 \\
Perceived stress & 3.77 & 0.97 & 0.270 & -0.177 & 0.844 \\
Well-being & 4.41 & 1.18 & -0.215 & \\
\hline
\end{tabular}


Table 2 Reliability and convergent validity

\begin{tabular}{llllll}
\hline & CR & AL & AVE & V AVE & Cronbach's $\alpha$ \\
\hline Fear of COVID-19 & 0.840 & 0.750 & 0.570 & 0.866 & 0.841 \\
Stress & 0.938 & 0.877 & 0.792 & 0.889 & 0.912 \\
Well-being & 0.843 & 0.781 & 0.578 & 0.760 & 0.844 \\
\hline
\end{tabular}

Note: $\mathrm{N}=625$. Cronbach's $\alpha$ on diagonal. $C R$, composite reliability; $A V E$, average variance extracted; $A L$ average loading

\section{Discussion and Implications}

The theoretical contributions of this study are multifold. First, "fear of COVID-19" has been introduced as a new variable to the existing literature on psychological constructs like fear and stress. The study contributed the perceived stress literature by exploring the relationship of FCV-19S. Fear of getting infected to COVID-19 is the major worry among the stressors during the pandemic and enhances the stress level among the people (Barzilay et al., 2020; Reznik et al., 2020).The present study also explored the relationship of fear of COVID-19 and stress among the people. Second, the study found out that fear of COVID-19 has shown a strong negative relationship with well-being. Thereby, fear of COVID-19 also marked its contribution to the studies on a person's well-being research through this study. This is consistent with the various outcomes of investigations that are being conducted recently in the field of COVID fear and well-being (Ahuja et al., 2020; Paredes et al., 2020; Reznik et al., 2020). Third, the study also projected the mediating role of stress between the fear of COVID-19 and wellbeing. As the effects of the fear enhances with stress associated with situation, it leads to more negative psychological effects and negative well-being (Ered et al., 2017; Zhang et al., 2016), and also proved through the present study.

The practical implications of the study draws more attention as the fear of COVID-19, at both individual and social levels, is pervasive in this pandemic period, and may lead to mental health problems (Tandon, 2020). Moreover, the main stressors for COVID infected/suspected individuals after their quarantine, are financial issues and stigma from surrounding environment (Ahorsu et al., 2020; Brooks et al., 2020; Ramaci et al., 2020). Especially among students, the pandemic scenario creates increased mood disorder symptoms, stress and an increased alcohol usage (Charles et al., 2021). Therefore, appropriate measures to cope with such situations must be discovered and adopted by the individuals, family, friends group etc.(Brooks et al., 2020; Ornell et al., 2020; Zacher \& Rudolph, 2020). Healthy and pleasant

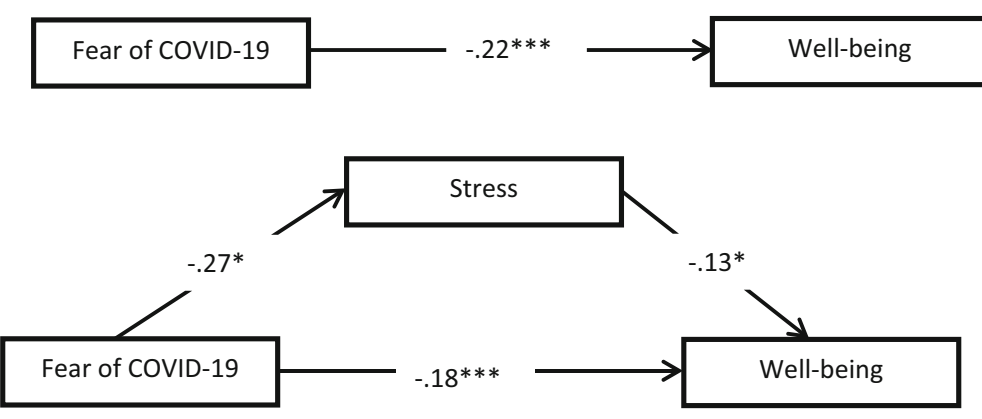

Fig. 2 Direct and indirect effects 
Table 3 Direct and indirect effects $(N=625)$

\begin{tabular}{lllll}
\hline Variable & $\boldsymbol{\beta}$ & $\mathbf{S E}$ & $\boldsymbol{t}$ & $\boldsymbol{p}$ \\
$\begin{array}{l}\text { Direct effect } \\
\text { Fear of COVID-19 } \rightarrow \text { stress }\end{array}$ & -.271 & .017 & 13.87 & .05 \\
Stress $\rightarrow$ well-being & -.133 & .013 & -11.18 & .05 \\
$\quad$ Fear of COVID-19 $\rightarrow$ well-being & $-.220^{*}$ & .031 & -7.95 & .001 \\
$\quad$ Variable & Value & SE & LL 95\% CI & UL 95\% CI \\
Bootstrap result for indirect effect & & & & -.062 \\
$\quad$ Fear of COVID $\rightarrow$ stress $\rightarrow$ well-being & -.035 & .018 & -.104 & \\
\hline
\end{tabular}

Bootstrap sample size $=2000 ; L L$, lower limit; $U L$, upper limit; $C I$, confidence interval

*Total effect

interactions among friends and relatives can help in overcoming fear and stress during the pandemic period (Brooks et al., 2020; Prime et al., 2020).

As there are movement restrictions and physical distance protocols that are strictly amended in societies, stress level may shoot-up, so, engaging oneself in different activities like listening to music, yoga, meditation, and physical activities may help (Giordano et al., 2020; Jasti et al., 2020). In addition, considering the societal aspects, online mental health counseling would help in maintaining a healthy mental state (Liu et al., 2020). College mental health professionals and parents need to provide proper awareness to students regarding the risks of drug and alcohol usage, which arise as a consequent of fear and stress due to pandemic situation (Charles et al., 2021). Policy makers must also consider such aspects of mental health wellbeing while planning pandemic response initiatives. Finally, educational institutions and government educational departments must also ensure that pandemic response measures are being strictly followed for the betterment of our student community.

The study has the following limitations. First, as with other studies in this area (Reznik et al., 2020; Satici et al., 2020), our study is cross-sectional and self-reported due to the unexpected restrictions due to pandemic. The self-reported data may have the implications of potential common method bias (Podsakoff et al., 2003). In order to reduce the effects of common method bias on our results, we used multi-item scales with high reliability (Spector, 1987). We have also incorporated the remedies suggested by experts to counteract these problems (Podsakoff et al., 2003). Further longitudinal studies in this area can be done to enhance the validity of our results. Moreover, future researches on different geographical regions can provide more generalizability of results in different contexts (Polit \& Beck, 2010). Second, the outcomes we have taken for the study are limited. Future studies can focus on more elaborate and diverse outcomes that can provide a more comprehensive picture of the situation.

\section{Conclusion}

A survey conducted among college students during the COVID-19 pandemic revealed that fear of pandemic affects their mental well-being by causing stress. As individual mental health plays an important role, this study provides some suggestions to educational institutions, i.e., to come up with pandemic response activities specifically to address the well-being of our student community. This study makes a wake-up call for the educational sectors to develop strategies to preserve mental health for future emergencies. 
Data Availability The data is openly available in World Health Organisation Report.

\section{Declarations}

Ethics Approval The research confined to the highest level of ethics.

Conflict of Interest The authors declare no competing interests.

\section{References}

Ahorsu, D. K., Lin, C. Y., Imani, V., Saffari, M., Griffiths, M. D., \& Pakpour, A. H. (2020). The fear of COVID19 scale: Development and initial validation. International Journal of Mental Health and Addiction. https:// doi.org/10.1007/s11469-020-00270-8.

Ahuja, K. K., Banerjee, D., Chaudhary, K., \& Gidwani, C. (2020). Fear, xenophobia and collectivism as predictors of well-being during coronavirus disease 2019: An empirical study from India. International Journal of Social Psychiatry, 1-8. https://doi.org/10.1177/0020764020936323

Arbuckle, J. L. (2016). IBM® SPSS® User's Guide Amos ${ }^{\mathrm{TM}}$ 24. IBM, Chicago, IL., 1-720. ftp://public.dhe.ibm.com.

Bagozzi, R., \& Yi, Y. (1988). On the evaluation of structure equation models. Ournal of the Academy of Marketing Science, 16(1), 74-94. https://doi.org/10.1007/BF02723327.

Barzilay, R., Moore, T. M., Greenberg, D. M., DiDomenico, G. E., Brown, L. A., White, L. K., Gur, R. C., \& Gur, R. E. (2020). Resilience, COVID-19-related stress, anxiety and depression during the pandemic in a large population enriched for healthcare providers. Translational Psychiatry, 10(1), 291. https://doi.org/10. 1038/s41398-020-00982-4.

Bernstein, C., \& Chemaly, C. (2017). Sex role identity, academic stress and wellbeing of first-year university students. Gender and Behaviour, 15(1), 8045-8069.

Blachnio, A., \& Przepiorka, A. (2017). Facebook intrusion, fear of missing out, narcissism, and life satisfaction: A crosssectional study. Psychiatry Research, 259, 514-519. https://doi.org/10.1016/j.psychres.2017.11.012.

Brooks, S. K., Webster, R. K., Smith, L. E., Woodland, L., Wessely, S., Greenberg, N., \& Rubin, G. J. (2020). The psychological impact of quarantine and how to reduce it: Rapid review of the evidence. The Lancet, 395(10227), 912-920. https://doi.org/10.1016/S0140-6736(20)30460-8.

Byrne, B. M. (2013). Structural equation modeling with AMOS: Basic concepts, applications, and programming. Routledge.

Cao, W., Fang, Z., Hou, G., Han, M., Xu, X., \& Dong, J. (2020). The psychological impact of the COVID-19 epidemic on college students in China. Psychiatry Research, 287, 112934.

Charles, N. E., Strong, S. J., Burns, L. C., Bullerjahn, M. R., \& Serafine, K. M. (2021). Increased mood disorder symptoms, perceived stress, and alcohol use among college students during the COVID-19 pandemic. Psychiatry Research, 296(June 2020), 113706. https://doi.org/10.1016/j.psychres.2021.113706.

Cohen, S., Kamarck, T., \& Mermelstein, R. (1983). A global measure of perceived stress. Journal of Health and Social Behavior, 24(4), 385-396.

Dodge, R., Daly, A., Huyton, J., \& Sanders, L. (2012). The challenge of defining wellbeing. International Journal of Wellbeing, 2(3), 222-235. https://doi.org/10.5502/ijw.v2i3.4.

Doty, D. H., \& Glick, W. H. (1998). Organizational Research Methods. Organizational Research Methods, 1(4), 374 406. https://doi.org/10.1177/109442819814002.

Dumalaon-canaria, J. A., Prichard, I., Hutchinson, A. D., \& Wilson, C. (2016). Fear of cancer recurrence and psychological well-being in women with breast cancer: The role of causal cancer attributions and optimism. European Journal of Cancer Care, 1, 1-12. https://doi.org/10.1111/ecc.12579

Ered, A., Gibson, L. E., Maxwell, S. D., Cooper, S., \& Ellman, L. M. (2017). Coping as a mediator of stress and psychotic-like experiences. European Psychiatry, 43, 9-13. https://doi.org/10.1016/j.eurpsy.2017.01.327.

Giordano, F., Scarlata, E., Baroni, M., Gentile, E., Puntillo, F., Brienza, N., \& Gesualdo, L. (2020). Receptive music therapy to reduce stress and improve wellbeing in Italian clinical staff involved in COVID-19 pandemic: A preliminary study. Arts in Psychotherapy, 70(June), 101688. https://doi.org/10.1016/j.aip. 2020.101688 .

Hall, D. L., Lennes, I. T., Pirl, W. F., Friedman, E. R., Elyse, R., Hospital, G., \& Hospital, M. G. (2017). Fear of recurrence or progression as a link between somatic symptoms and perceived stress among cancer survivors. Supportive Care in Cancer, 25(5), 1401-1407. https://doi.org/10.1007/s00520-016-3533-3.Fear.

Heymann, D. L., \& Shindo, N. (2020). COVID-19: What is next for public health? The Lancet, 395(10224), 542-545. https://doi.org/10.1016/S0140-6736(20)30374-3. 
Holmes, E. A., O’Connor, R. C., Perry, V. H., Tracey, I., Wessely, S., Arseneault, L., Ballard, C., Christensen, H., Cohen Silver, R., Everall, I., Ford, T., John, A., Kabir, T., King, K., Madan, I., Michie, S., Przybylski, A. K., Shafran, R., Sweeney, A., ... Bullmore, E. (2020). Multidisciplinary research priorities for the COVID19 pandemic: A call for action for mental health science. The Lancet Psychiatry, 7, 547-560. https://doi.org/ 10.1016/S2215-0366(20)30168-1.

Hu, L. T., \& Bentler, P. M. (1998). Fit indices in covariance structure modeling: Sensitivity to underparameterized model misspecification. Psychological Methods, 3(4), 424-453. https://doi.org/10. 1037/1082-989X.3.4.424.

Jasti, N., Bhargav, H., George, S., Varambally, S., \& Gangadhar, B. N. (2020). Tele-yoga for stress management: Need of the hour during the COVID-19 pandemic and beyond? Asian Journal of Psychiatry, 54, 18-20. https://doi.org/10.1016/j.ajp.2020.102334.

Kim, U., Bhullar, N., \& Debra, J. (2020). Life in the pandemic: Social isolation and mental health. 2756-2757. https://doi.org/10.1111/jocn.15290

Koch, L., Jansen, L., Brenner, H., \& Arndt, V. (2012). Fear of recurrence and disease progression in long-term ( $\geq 5$ years ) cancer survivors-A systematic review of quantitative studies. Psycho-Oncology, 22(1), 1-11.

Lathabhavan, R., \& Griffiths, M. D. (2020). First case of student suicide in India due to the COVID-19 education crisis: A brief report and preventive measures. Asian Journal of Psychiatry.

Lee, E. (2012). Review of the psychometric evidence of the perceived stress scale. Asian Nursing Research, 6(4), 121-127. https://doi.org/10.1016/j.anr.2012.08.004.

Liu, S., Yang, L., Zhang, C., Xiang, Y. T., Liu, Z., Hu, S., \& Zhang, B. (2020). Online mental health services in China during the COVID-19 outbreak. The Lancet Psychiatry, 7(4), e17-e18. https://doi.org/10.1016/ S2215-0366(20)30077-8.

Maeng, L. Y., \& Milad, M. R. (2017). Post-traumatic stress disorder : The relationship between the fear response and chronic stress. Chronic Stress, 1, 1-13. https://doi.org/10.1177/2470547017713297.

Mamun, M. A., Chandrima, R. M., \& Griffiths, M. D. (2020). Mother and son suicide pact due to COVID-19related online learning issues in Bangladesh: An unusual case report mother and son suicide pact due to COVID-19-related online learning issues in Bangladesh: An unusual case report. International Journal of Mental Health and Addiction. https://doi.org/10.1007/s11469-020-00362-5.

Nunnally, J. C. (1994). Psychometric theory. Tata McGraw-hill education.

Ornell, F., Schuch, J. B., Sordi, A. O., \& Kessler, F. H. P. (2020). "Pandemic fear" and COVID-19: Mental health burden and strategies. Brazilian Journal of Psychiatry, 42(3), 232-235. https://doi.org/10.1590/15164446-2020-0008.

Pakpour, A. H., \& Griffiths, M. D. (2020). The fear of COVID-19 and its role in preventive behaviors. Journal of Concurrent Disorders, 2020.

Paredes, M. R., Apaolaza, V., Fernandez-robin, C., Hartmann, P., \& Yañez-martinez, D. (2020). The impact of the COVID-19 pandemic on subjective mental well-being: The interplay of perceived threat, future anxiety and resilience. Personality and Individual Differences, 170, 1-6.

Podsakoff, P. M., Mackenzie, S. B., Lee, J., \& Podsakoff, N. P. (2003). Common method biases in behavioral research: A critical review of the literature and recommended remedies. Journal of Applied Psychology, 88(5), 879-903. https://doi.org/10.1037/0021-9010.88.5.879.

Polit, D. F., \& Beck, C. T. (2010). Generalization in quantitative and qualitative research: Myths and strategies. International Journal of Nursing Studies, 47(11), 1451-1458. https://doi.org/10.1016/j.ijnurstu.2010.06.004.

Praharso, N. F., Tear, M. J., \& Cruwys, T. (2017). Stressful life transitions and wellbeing: A comparison of the stress buffering hypothesis and the social identity model of identity change. Psychiatry Research, 247(January), 265-275. https://doi.org/10.1016/j.psychres.2016.11.039.

Prime, H., Wade, M., \& Browne, D. T. (2020). Risk and resilience in family well-being during the COVID-19 pandemic. American Psychologist, 75(5), 631-643. https://doi.org/10.1037/amp0000660.

Ramaci, T., Barattucci, M., Ledda, C., \& Rapisarda, V. (2020). Social stigma during COVID-19 and its impact on HCWs outcomes. Sustainability (Switzerland), 12(9), 1-13. https://doi.org/10.3390/su12093834.

Reznik, A., Gritsenko, V., Konstantinov, V., Khamenka, N., \& Isralowitz, R. (2020). COVID-19 fear in Eastern Europe: Validation of the fear of COVID-19 scale. International Journal of Mental Health and Addiction, 1-6.

Satici, B., Gocet-tekin, E., Deniz, M. E., \& Satici, S. A. (2020). Adaptation of the fear of COVID-19 scale: Its association with psychological distress and life satisfaction in Turkey. International Journal of Mental Health and Addiction.

Spector, P. E. (1987). Method variance as an artifact in self-reported affect and perceptions at work: Myth or significant problem ? Journal of Applied Psychology, 72(3), 438-441.

Tandon, R. (2020). COVID-19 and mental health: Preserving humanity, maintaining sanity, and promoting health. Asian Journal of Psychiatry, 51, 102256.

Thakur, V., \& Jain, A. (2020). COVID 2019-suicides: A global psychological pandemic. Brain, Behavior, and Immunity, 88(January), 952-953. 
Torales, J., Higgins, M. O., Castaldelli-maia, J. M., \& Ventriglio, A. (2020). The outbreak of COVID-19 coronavirus and its impact on global mental health. International Journal of Social Psychiatry, 1-4. https://doi.org/10.1177/0020764020915212

Xiong, J., Lipsitz, O., Nasri, F., Lui, L. M. W., Gill, H., \& Phan, L. (2020). Impact of COVID-19 pandemic on mental health in the general population: A systematic review. Journal of Affective Disorders, 277, 55-64.

Yang, C., Dillard, J. P., \& Li, R. (2018). Understanding fear of Zika: personal, interpersonal, and media influences. Risk Analysis, 38(12), 2535-2545. https://doi.org/10.1111/risa.12973.

Zacher, H., \& Rudolph, C. W. (2020). Individual differences and changes in subjective wellbeing during the early stages of the COVID-19 pandemic. American Psychologist, 76, 1-13. https://doi.org/10.1037/ amp0000702.

Zhang, M., Hong, L., Zhang, T., Lin, Y., Zheng, S., Zhou, X., Fan, R., Wang, Z., Zhang, C., \& Zhong, J. (2016). Illness perceptions and stress: Mediators between disease severity and psychological well-being and quality of life among patients with Crohn's disease. Patient Preference and Adherence, 10, 2387-2396. https://oi. org/10.2147/PPA.S118413.

Publisher's Note Springer Nature remains neutral with regard to jurisdictional claims in published maps and institutional affiliations. 